\section{Water pipe tobacco smoking: are the Bahraini smokers aware of its health effects?}

\author{
Ebrahim Khalil, Sajida Mansor Ayyad, \\ Fatima S. Sharaf Al-Alawi, Hasan A. Ali \\ Khalil, Muyassar Sabri Hassan Awadalla, \\ Govindaraj Vaithinathan Asokan \\ College of Health Sciences, WHO \\ Collaborating Centre for Nursing \\ Education, University of Bahrain, \\ Salmanya Medical Complex, Kingdom \\ of Bahrain
}

\section{Abstract}

The tobacco epidemic kills half of its users annually and 600,000 deaths occur in people exposed to cigarette and water pipe tobacco (WT) smoking. A population-based cross sectional study was conducted to explore the knowledge and perceptions on health effects of WT smoking amongst Bahraini adults in the popular coffee shops of Bahrain and in women's congregations. Randomly, 206 Bahraini adults of both genders were selected and distributed with a developed questionnaire to collect data; results were analyzed using SPSS (SPSS Inc., Chicago, IL, USA). Among the WT smokers, the highest proportion (45\%) was observed between 21 and 30 age group and in the higher educational category. Majority smoked daily. The leading motives of WT smoking were meeting friends, passing of time and pleasure. Many smokers believed WT as less harmful than cigarettes, but affect the respiratory system, and causes: cancers, cardiovascular disease and pregnancy-related disorders. The knowledge scores were significantly higher in the younger age group, higher educational qualifications, and higher income. A considerable proportion of smokers perceived WT smoking as a sign of maturity, acceptable by the society. The perception scores were significantly higher in women and in the age group of $>40$. This study has revealed a lack of knowledge amongst the Bahraini adults who assume that health risks of WT are lower than cigarettes demanding further research to evaluate WT smoking risks, health effects, environmental effects of smoke, and regulatory services in Bahrain for a responsive approach to curb the WT tobacco epidemic.

\section{Introduction}

The global tobacco epidemic kills half of its users annually accounting up to 6 million deaths. An additional, 600,000 deaths occur in non-smokers being exposed to second-hand smoke from cigarette and water pipe tobacco (WT) smoking at confined places. ${ }^{1}$ Often, WT smoking occurs in groups as a social activity that has a history of at least 400 years in the Middle East, India, and parts of Asia. WT varies in size and shape; it is also known as shisha, hookah, narghile, goza, and hubble bubble. The specially made tobacco in water pipe comes in different flavors and the popular flavors are: apple, banana, berry, cherry, chocolate, cappuccino, coconut, mint, licorice and watermelon. Sweeter additives and flavors were developed to attract female consumers. ${ }^{2}$

All forms of tobacco smoking are harmful to health. More than 4000 chemicals in tobacco smoke have been identified; at least 250 are known to be harmful and more than 60 are known to cause cancer. Toxic trace metals have been found in herbal shisha products and their smoke emissions contained carcinogens equivalent to, or in excess of, those of tobacco products. ${ }^{3}$ A meta-analysis of data from four nations indicated that daily use of WT produced nicotine absorption of a magnitude similar to that produced by daily cigarette use. ${ }^{4}$ Smoking WT for approximately 20 to $80 \mathrm{~min}$ is equivalent to smoking 100 or more of cigarettes. ${ }^{5}$ Besides, smoking WT produces more second hand smoke than cigarettes; thereby, passive smokers are at similar risk for the diseases caused by cigarette smoking. Existing evidence of diseases as a result of WT smoking includes lung cancer, oral cancer, stomach cancer, cardiovascular and respiratory diseases, reduced lung function, coronary heart disease and adverse effects during pregnancy. Babies born to mothers who smoked WT weighed less at birth ${ }^{6}$ and were also found to be at increased risk of respiratory diseases. The risks of contracting infectious diseases and the opportunity to spread arise from the shared mouthpiece of water pipe and moist smoke. WT smoking has been associated with outbreaks in the Middle East; for instance, two outbreaks in 2010, which revealed a possible association between tuberculosis and sharing a WT pipe. ${ }^{7}$

Factors attributed to WT smoking comprise social acceptability, lack of knowledge of health effects, and concentrated preventive programs to cigarette more than WT smoking. . $^{8} 9$ Lingering popular myths of WT smoking are: i) WT is less harmful and addictive than cigarettes; ii) nicotine content in WT is lower than that of cigarettes and water used in WT filters all the hazardous chemicals such as carbon monoxide, tar and nicotine. ${ }^{10}$ On the other hand, water in the pipe partially cools the smoke, makes it less irritating by its taste, smell and smoothness of sweetened tobacco. Yet, by all yardsticks, WT is not less toxic; greater exposure to toxins with higher nicotine intake results from more frequent puffs and longer sustained sessions. Further, frequent use of WT is a determinant for addiction
Correspondence: Govindaraj Vaithinathan Asokan, College of Health Sciences, University of Bahrain, Salmanya Medical Complex, P.0. Box 32038, Kingdom of Bahrain.

Tel.: 00973.17285421 - Mobile: 00973.39497564. E-mail: agvaithinathan@uob.edu.bh

Key words: Water pipe; smoking; health effects.

Acknowledgments: the authors are grateful to Dr. Aneesa Al-Sindi, Dean, College of Health Sciences, University of Bahrain for the support and encouragement provided in this work. The authors would like to thank Mr. Hasan Al Basri for statistical assistance.

Contributions: GVA, idea conceiving; EK, SMA, HAAK, data collection; MSHA data interpretation. All authors contributed equally in drafting and editing the manuscript.

Conflict of interest: the authors declare no potential conflict of interest.

Received for publication: 1 June 2015. Revision received: 3 September 2015 .

Accepted for publication: 3 September 2015.

This work is licensed under a Creative Commons Attribution NonCommercial 3.0 License (CC BYNC 3.0).

(C) Copyright E. Khalil et al., 2015

Licensee PAGEPress, Italy

Nursing Reports 2015; 5:5306

doi:10.4081/nursrep.2015.5306

similar to cigarettes. ${ }^{11}$ Over the past several years, a global upsurge of WT smoking has been recorded in the Middle East, USA, Canada, France, Russia, UK and Australia owing to the increasing popularity amongst young people. In the West: more than half of the young population in Denmark reported tried smoking WT, ${ }^{12}$ and a Canadian study on nicotine dependence in teens, reported 23\% WT use. ${ }^{13}$ In the Arab World: a premarital screening program in Abu Dhabi recorded 4.8\% smoking WT; ${ }^{14}$ amongst Egyptian female university students, $37.8 \%$ smoked WT only, and $35.2 \%$ smoked both WTS and cigarettes, ${ }^{15}$ and the prevalence of WT smoking amongst male medical students in Saudi Arabia ${ }^{16}$ was $12.6 \%$ and was lower compared with the prevalence in dental students. According to the National non-communicable diseases (NNCDs) risk factor survey of 2007, Bahrain, ${ }^{17}$ the prevalence rate of tobacco use was $23.1 \%$ and smoking WTS was $8.4 \%$. WT smoking was higher amongst males, particularly in young adults between the age group of 20 and 29 (17.8\%). Amongst females, the prevalence rate was higher in older women between the age group of 50 and 64 (11.5-13.2\%).

Governmental and non-governmental 
healthcare organizations have a shared commitment to tobacco control in which nurses are a vital force in the interdisciplinary health care team. More specifically, public health or community nurses have a greater role in tobacco cessation practices as public health nursing involves working with communities and populations as partners, focusing on primary prevention and health promotion. Public health nurses practice in diverse settings. High-risk and vulnerable populations are often the focus of care that includes WT smokers. ${ }^{18}$

With deep-seated myths amongst smokers of WT, we hypothesized a significant relationship between adults smoking WT and their low level of knowledge on its health effects in Bahrain. Although, objectively, the NNCD survey has estimated the prevalence of WT smoking amongst adults in Bahrain along with other non-communicable diseases, the survey did not examine their knowledge or perceptions regarding non communicable diseases, or health effects resulting from the use of tobacco in any form. The aim of this study was to explore the knowledge and perceptions on health effects of WT smoking amongst adults in Bahrain.

\section{Materials and Methods}

A population based cross sectional study was conducted during 2014, in the most populated and diverse (traditional and non-traditional) coffee shops of Bahrain that catered WT, as well as in women matams (places of religious and social congregation) where women smoke WT, within the three governorates of Bahrain i.e., Northern, Capital and Muharaq. A random sampling process was followed in selecting the governorates, coffee shops/matams and participants. A sample size of 140 WT smokers was required for the $\mathrm{NNCD}^{16}$ survey reported prevalence of $8.4 \%$ of WT smoking in Bahraini population to give a $95 \%$ chance of being within $5 \%$ of the true result allowing for up to $10 \%$ of invalid or missing responses.

Based on an in-depth literature review of smoking, socio-cultural aspects and health effects of WT, the data collection instrument was designed. The instrument was structured and sequentially ordered with the following four sections: i) demography of the participants that included age, gender, highest attained educational level and monthly income (Table 1); ii) general information regarding WT smoking that included age at initiation of WT smoking, primary motives, frequency, time spent in a smoking session, cost per smoking session, preferred flavor and attempts to quit WT smoking; iii) knowledge on health effects of WT smoking with a binary (true/false) response (Table 2); and iv) perceptions on WT smoking on a five point Likert scale (Table 3 ). The questionnaire was built in English language and translated to Arabic language. Back translation of the Arabic version of the questionnaire to English language ensured retention of the originality of the questions. For affirming face and content validity, the questionnaire was scrutinized by a panel of experts from College of Health Sciences, University of Bahrain. Pre-testing and piloting our questionnaire in thirty WT smokers (coffee shops $\mathrm{n}=15$, matams $\mathrm{n}=15$ ) rendered suitable modifications to the questionnaire before embarking the main study. The developed questionnaire used in the study was specific, realistic and measurable that had an acceptable internal consistency (Cronbach's $\alpha=0.61$ ).

Generally, by late evenings the coffee shops are vibrant with customers and data collection was accomplished during such ideal time. Bahraini adults aged 18 years and above, in both genders, who are WT smokers in the coffee shops and matams were alone included in the study. After briefing the study purpose, each one was provided with a self-administered questionnaire to complete it with their responses. Informed consent was obtained from the participants without persuasion. Confidentiality, anonymity and data of the participants gathered were protected throughout the study and after. The data from the questionnaire was cleaned, categorized, coded and entered in Excel (Microsoft, Redmond, WA, USA), exported to SPSS version 21 for windows (SPSS Inc., Chicago, IL, USA), for descriptive and inferential statistical analysis. The College of Health Sciences research committee has approved the study.

Table 1. Demographic data.

\begin{tabular}{lccc}
\multicolumn{2}{c}{ Demographic characteristics } & n=206 & Percentage \\
Age & $<=20$ & 36 & 17.5 \\
& $21-30$ & 93 & 45.1 \\
\hline \multirow{2}{*}{ Gender } & $31-40$ & 40 & 19.4 \\
& $>40$ & 37 & 18.0 \\
\hline Educational level & Male & 174 & 84.5 \\
& Female & 32 & 15.5 \\
\hline \multirow{3}{*}{ Monthly income } & $<$ High School & 32 & 15.5 \\
\hline & High School Completed & 80 & 38.8 \\
\hline & College Graduate or above & 94 & 45.6 \\
\hline & No income & 56 & 27.2 \\
\hline
\end{tabular}

\section{Results}

A total of two hundred and six participants participated in the study and the gender distribution was skewed (male: 174, female: 32 ). Among the four categorized age groups, the highest proportion (45\%) of WT smokers was observed in the age group between 21 and 30 .

Participants with college degree/equivalent/other higher degrees had the highest proportion (45\%) of smoking WT, whereas, no explicit variation among the four categories of income was noticeable (Table 1). The mean age of the smokers was 30 , declared age at initiation of smoking WT was 19 and an average time spent in a smoking session was 75 min. Through a solitary attempt, $47 \%$ of the participants had admitted to have made efforts to quit smoking WT.

The three leading motives of WT smoking were meeting friends and family (45\%) followed by boredom/passing of time (25\%) and pleasure/happiness (16\%). Among the frequency of WT smoking, majority (55\%) smoked daily and $25 \%$ smoked during weekends. The bulk of the smokers (46\%) recalled spending US $\$ 2.5$ to 5 per smoking session and the most preferred flavors of WT were apple (27\%), grape (22\%) and grape with mint (19\%).

Table 2 describes the binary responses of the participants' knowledge about the health effects of WT smoking. Many smokers believed WT: less harmful compared to cigarettes (60\%), affects the respiratory system (89\%), leads to lung cancer, oral cavity cancer, and tongue cancer (73\%), causes cardiovascular diseases/hypertension (67\%) and responsible for the most pregnancy related disorders (83\%). The for and against views on transmission of infections through smoking WT were even. Contrary to the fair knowledge on above 
stated health effects, two thirds of the smokers presumed that smoking WT does not affect sexual ability or cause infertility or affect concentration and attention. In aggregate, the knowledge scores (mean: 5.47) were significantly higher in the groups of: 21-30 age $(\mathrm{P}<0.02)$, higher educational qualifications $(\mathrm{P}<0.002)$, and in higher income $(\mathrm{P}<0.02)$.

The perceptions of WT smokers described in Table 3 are: one third of them agreed that compared to cigarettes, WT is accepted by the society, however, half of them strongly agreed that the parents would object their son/daughter smoking WT and most felt smoking WT is a sign of maturity. One fourth disagreed with the notion that WT smokers have more friends than non-smokers. A strong resentment (45\%) was observed for women smoking WT. One third of the smokers strongly disagreed that teenagers smoke WT to imitate celebrities. In aggregate, the perception scores were significantly higher in: the age group of $>40$ $(\mathrm{P}<0.02)$ and women $(\mathrm{P}<0.001)$.

\section{Discussion}

Global disease patterns have changed from infectious diseases to predominantly chronic diseases and injuries. Tobacco use is considered as the leading preventable cause of most morbidity and mortality of chronic diseases such as cardiac diseases and cancer. By and large, scientific research and cessation methods of tobacco have focused on cigarette smoking. Often, WT has not been regarded in parallel to that of cigarettes in smoking cessation methods. Although, smoking WT is a global health concern, a bibliometric analysis has reported marginal research addressing tobacco smoking using WT, ${ }^{19}$ despite WT smoking gaining popularity over the past two decades..$^{20,21}$ Evidence accumulated so far suggests that some WT smokers become addicted, face difficulty quitting, and experience health risks similar to cigarette smokers. ${ }^{22}$ To advance knowledge, promote action, and sustainable implementation of health policies must be based on reliable estimates and understandings of any misconceptions, prevailing knowledge and perceptions. Yet, no reports documented in Bahrain on the knowledge or perceptions regarding health effects result from the use of WT amongst adults. Therefore, this study was purported to examine the use of WT in Bahrain and to recommend necessary measures to promote health by cessation of WT smoking. Our study has revealed that most water pipe tobacco smokers were around 30 years, have higher educational qualifications, smoked daily, frequently with friends or families. Complementary to our findings, the NNCD survey in Bahrain, ${ }^{16}$ and a report from the Arab world ${ }^{23}$ considered WT as a major tobacco use method amongst the youths of
Bahrain and the Gulf region. Alarmingly, the average time spent in a smoking session of 75 min found in our study is reckoned to smoking 100 or more of cigarettes according to the tobacco product regulation advisory note. ${ }^{5}$ Smokers with higher income, higher educational qualifications and aged between 21 and 30 had significantly higher knowledge scores than others but their illusion of WT as less harmful than cigarettes and accepted by the society is baffling. The prevailing myths of the WT smokers in our study were similar to a reported perception of medical students in Malaysia $^{24}$ but contrary to a report from Pakistan, where majority considered WT more dangerous than cigarettes. ${ }^{25}$ Notably, with the highest perception scores amongst participants over 40 years of age and women, most of them perceived their parents would object

Table 2. Knowledge about the health effects of water pipe smoking.

\begin{tabular}{|c|c|c|c|c|}
\hline \multirow[t]{2}{*}{ Knowledge on health effects $(n=206)$} & \multicolumn{2}{|c|}{ True } & \multicolumn{2}{|c|}{ False } \\
\hline & n & $\%$ & n & $\%$ \\
\hline $\begin{array}{l}\text { I consider water pipe smoking is less harmful } \\
\text { compared to cigarettes smoking }\end{array}$ & 83 & 59.7 & 83 & 40.3 \\
\hline $\begin{array}{l}\text { Cigarettes contain less content of harmful } \\
\text { substances than water pipe }\end{array}$ & 140 & 32.0 & 140 & 68.0 \\
\hline $\begin{array}{l}\text { Water pipe smoking causes damage } \\
\text { to the respiratory system }\end{array}$ & 23 & 88.8 & 23 & 11.2 \\
\hline $\begin{array}{l}\text { Water pipe smoking leads to lung cancer, } \\
\text { oral cavity cancer, and tongue cancer }\end{array}$ & 56 & 72.8 & 56 & 27.2 \\
\hline Water pipe smoking may transmit infections & 107 & 48.1 & 107 & 51.9 \\
\hline Water pipe smoking causes stomach ulcer & 136 & 34.0 & 136 & 66.0 \\
\hline $\begin{array}{l}\text { Water pipe smoking causes cardiovascular } \\
\text { diseases and hypertension }\end{array}$ & 68 & 67.0 & 68 & 33.0 \\
\hline $\begin{array}{l}\text { Water pipe smoking causes } \\
\text { pregnancy related problems }\end{array}$ & 35 & 83.0 & 35 & 17.0 \\
\hline $\begin{array}{l}\text { Water pipe smoking causes affects sexual } \\
\text { ability and may cause infertility in men }\end{array}$ & 143 & 30.6 & 143 & 69.4 \\
\hline $\begin{array}{l}\text { Water pipe smoking affects the ability of } \\
\text { concentration and attention }\end{array}$ & 143 & 30.6 & 143 & 69.4 \\
\hline
\end{tabular}

Values in italics represent higher proportion.

Table 3. Perceptions of water pipe smoking.

\begin{tabular}{|c|c|c|c|c|c|c|c|c|c|c|}
\hline \multirow{2}{*}{ Perception $(\mathrm{n}=206)$} & \multicolumn{2}{|c|}{ Strongly disagree } & \multicolumn{2}{|c|}{ Disagree } & \multicolumn{2}{|c|}{ Undecided } & \multicolumn{2}{|c|}{ Agree } & \multicolumn{2}{|c|}{ Strongly agree } \\
\hline & n & $\%$ & n & $\%$ & n & $\%$ & n & $\%$ & n & $\%$ \\
\hline $\begin{array}{l}\text { Water pipe smoking is more acceptable } \\
\text { by the society compared to cigarettes }\end{array}$ & 28 & 13.6 & 25 & 12.1 & 38 & 18.4 & 71 & 34.5 & 44 & 21.4 \\
\hline $\begin{array}{l}\text { Parents would object their son/daughter } \\
\text { smoking water pipe }\end{array}$ & 15 & 7.3 & 12 & 5.8 & 29 & 14.1 & 54 & 26.2 & 96 & 46.6 \\
\hline Water pipe smoking is a sign of maturity & 37 & 18.0 & 30 & 14.6 & 40 & 19.4 & 50 & 24.3 & 49 & 23.8 \\
\hline $\begin{array}{l}\text { Water pipe smokers believe that they } \\
\text { have more friends than non-smokers }\end{array}$ & 36 & 17.5 & 50 & 24.3 & 48 & 23.3 & 40 & 19.4 & 32 & 15.5 \\
\hline Woman smoking water pipe is socially accepted & 92 & 44.7 & 36 & 17.5 & 36 & 17.5 & 21 & 10.2 & 21 & 10.2 \\
\hline Teenagers smoke water pipe to imitate celebrities & 69 & 33.5 & 44 & 21.4 & 42 & 20.4 & 25 & 12.1 & 26 & 12.6 \\
\hline
\end{tabular}

Values in italics represent higher proportion. 
smoking WT. Whereas, a cause for concern is that a considerable proportion considered the practice of WT smoking as a sign of maturity. In addition, women smoking WT was disagreeable to most of our study participants probably owing to more men in our study sample who still consider smoking in any form is a male domain.

Tobacco use in Bahrain is strictly under control that includes higher taxes, ban of tobacco smoking in public places and advertising in the media, and prohibition of sale of tobacco products to children. Despite the existence of these regulations, tobacco use in any form seems to be high in Bahrain. The new national guidelines on smoking cessation in Bahrain attempt to integrate primary health care into smoking cessation services. ${ }^{26}$ Such an integration requires providing leadership roles to public health or community nurses for an effective policy to practice translation. The public health nurses' leadership role would make an assessment of assets and needs of communities and populations and propose solutions in partnership. Population focused solutions is expected to have widespread influence on health beginning from individuals, families, groups, neighborhoods, communities, and to the broader population through collaboration with agencies and communities for community organizing, health promotion and advocacy for WT smoking cessation.

Certain limitations in our study warrant care in the interpretation of the results. First, WT smokers at coffee shops and matams provided a sample chosen randomly on the elected survey days; they were relatively accessible, and cooperative, but, the elected days did not represent the entire population visiting the coffee shops which are not uncommon in cross sectional studies of this nature. Second, the WT smoking was only corroborated by the NNCD survey data of 2007. Third, we have interviewed only current WT smokers and our questionnaire did not include switching-smoker from cigarette to WT or use of any other form of tobacco use currently. Fourth, health effects attributable to the mainstream and side stream smoke emanating from WT at confined places that are more harmful to non-smokers particularly to children and the elderly has not been assessed.

\section{Conclusions}

This study has revealed a lack of knowledge amongst the younger population of Bahrain who assume health risks of WT are lower than cigarettes. It has been found that WT is socially accepted tool for socialization in coffee shops, homes and matams; it can be expected that the magnitude of WT smokers is high. However, it is evident from our study that parents disapprove their son/daughter smoking WT and the attitude scores were higher for smokers $>40$ years of age, which indicates that parents can be further motivated to restrain their son/daughter against smoking WT.

To bridge the gap between research on WT smoking and health promotion, evaluation of: WT smoking risks, health effects, environmental effects that include main stream and side stream smoke, and regulatory services in Bahrain are required by undertaking further studies. Owing to the unique features of WT and the misconceptions about health risks, specific evidence based public health policy interventions are required to equip the public to clear the misconceptions and make informed decisions about WT smoking. Such interventions should be synonymous to cigarette cessation methods. Above all, we must develop a more proactive rather than responsive approach for tobacco control to curb the WT tobacco epidemic.

\section{References}

1. World Health Organization Media Centre. Tobacco; Fact sheet $\mathrm{N}^{\circ} 339$ - November 2014. Available from: http://www.who.int/ mediacentre/factsheets/fs339/en/ Accessed: May 21, 2014.

2. American Lung Association. An emerging deadly trend: water pipe tobacco use; February 2007. Available from: http://www. lungusa2.org/embargo/slati/Trendalert_W aterpipes.pdf Accessed: September 27, 2014.

3. Hammal F, Chappell A, Wild TC, et al. 'Herbal' but potentially hazardous: an analysis of the constituents and smoke emissions of tobacco-free water pipe products and the air quality in the cafes where they are served. Tob Control 2015;24:290-7.

4. Neergaard J, Singh P, Job J, Montgomery S. Water pipe smoking and nicotine exposure: a review of the current evidence. Nicotine Tob Res 2007;9:987-94.

5. World Health Organization Study group on Tobacco Product Regulation (TobReg). Advisory note - Water-pipe tobacco smoking: health effects, research needs and recommended actions by regulators; September 2014. Available from: http:// www.who.int/tobacco/global_interaction/to breg/Waterpipe\%20recommendation_Fina l.pdf

6. Nuwayhid IA, Yamout B, Azar G, Kambris MA. Narghile (hubble-bubble) smoking, low birth weight, and other pregnancy outcomes. Am J Epidemiol 1998;148:375-83.

7. Akl EA, Gaddam S, Gunukula SK, et al. The effects of water pipe tobacco smoking on health outcomes: a systematic review. Int J Epidemiol 2010;39:834-57.

8. Amin TT, Amr MA, Zaza B0, Kaliyadan F. Predictors of water pipe smoking among secondary school adolescents in $\mathrm{Al}$ Hassa,Saudi Arabia. Int $\mathbf{J}$ Behav Med 2012;19:324-35.

9. St Helen G, Benowitz NL, Dains KM, et al. Nicotine and carcinogen exposure after water pipe smoking in hookah bars. Cancer Epidemiol Biomarkers Prev 2014;23:1055-66.

10. Sameer-ur-Rehman, Sadiq MA, Parekh MA, et al. Cross-sectional study identifying forms of tobacco used by Shisha smokers in Pakistan. J Pak Med Assoc 2012;62:192-5.

11. Maziak W, Ward KD, Eissenberg T. Factors related to frequency of narghile (water pipe) use: the first insights on tobacco dependence in narghile users. Drug Alcohol Depend 2004;76:101-6.

12. Døssing M. Water-pipe smoking - a survey of a Cochrane review. Ugeskr Laeger 2009;171:2721-3 [In Danish].

13. Dugas E, Tremblay M, Low NC, et al. Water-pipe smoking among North American youths. Pediatrics 2010;125: 1184-9.

14. Aden B, Karrar S, Shafey 0, Al Hosni F. Cigarette, water-pipe, and medwakh smoking prevalence among applicants to $\mathrm{Abu}$ Dhabi's pre-marital screening program, 2011. Int J Prev Med 2013;4:1290-5.

15. Labib N, Radwan G, Mikhail N, et al. Comparison of cigarette and water pipe smoking among female university students in Egypt. Nicotine Tob Res 2007;9: 591-6.

16. Taha AZ, Sabra AA, Al-Mustafa ZZ, et al. Water pipe (shisha) smoking among male students of medical colleges in the eastern region of Saudi Arabia. Ann Saudi Med 2010;30:222-36.

17. Ministry of Health. Kingdom of Bahrain. National Non-communicable Diseases Risk Factors survey 2007. Ministry of Health. Available from: http://www.who. int/chp/steps/2007_STEPS_Survey_Bahrai n.pdf Accessed: February 21, 2015.

18. Kulbok PA, Thatcher E, Park E, Meszaros P. Evolving public health nursing roles: focus on community participatory health promotion and prevention. Online J Issues Nurs 2012;17:1.

19. Zyoud SH, Al-Jabi SW, Sweileh WM. Bibliometric analysis of scientific publications on water pipe (narghile, shisha, hookah) tobacco smoking during the period 2003-2012. Tob Induc Dis 2014;12:7.

20. Maziak W. The global epidemic of water pipe smoking. Addict Behav 2011;36:1-5.

21. Maziak W, Ward KD, Afifi Soweid RA, Eissenberg T. Tobacco smoking using a water pipe: a re-emerging strain in a glob- 
al epidemic. Tob Control 2004;13:327-33.

22. Maziak W, Jawad M, Jawad S, et al. Interventions for water pipe smoking cessation. Cochrane Database Syst Rev 2015;7:CD005549.

23. Maziak W, Nakkash R, Bahelah R, et al. Tobacco in the Arab world: old and new epidemics amidst policy paralysis. Health Policy Plan 2014;29:784-94.
24. Al-Naggar RA, Bobryshev YV. Shisha smoking and associated factors among medical students in Malaysia. Asian Pac J Cancer Prev 2012;13:5627-32.

25. Haroon M, Munir A, Mahmud W, et al. Knowledge, attitude, and practice of waterpipe smoking among medical students in Rawalpindi, Pakistan. J Pak Med Assoc 2014;64:155-8.
26. Ministry of Health. Kingdom of Bahrain. Bahrain's Health Agenda. Health Improvement Strategy. National action plan for prevention and control of non communicable diseases in the kingdom of Bahrain: Integrated framework for Action. Report of the Ministry of Health Bahrain; 2012. Accessed: March 19, 2015. 